Gazi University
Journal of Science
$\mathrm{http} / /$ dergipark.gov.tr/gujs

\title{
Mechanical and Physical Characteristics of Bubble Alumina Reinforced Aluminum Syntactic Foams Made Through Recyclable Pressure Infiltration Technique
}

\author{
Cagın BOLAT ${ }^{*}$ (i) , Cem BEKAR ${ }^{(1)}$, Ali GOKSENLI (i) \\ Istanbul Technical University, Faculty of Mechanical Engineering, 34437, Istanbul, Turkey
}

\author{
Highlights \\ - This paper focuses on mechanical properties of bubble alumina reinforced Al 7075 syntactic foam \\ - A novel recyclable infiltration casting is proposed for foam fabrication. \\ - T6 heat treatment improves compressive features of fabricated foam samples. \\ - T6 heat treatment causes brittle style deformation compared to as-cast versions.
}

Article Info

Received: 06 Jan 2021

Accepted: 06 Mar 2021

Keywords

Syntactic foams

Heat treatment

Casting

Compressive

properties

Fracture characteristic

\begin{abstract}
Metal matrix syntactic foams (MMSFs) are advance hybrid materials which reflect synergetic combination of particle reinforced composites and close cell metal foams. Recently, MMSFs have become considerably popular for several industrial areas because of their low density, high compression strength, good ductility and perfect energy absorption ability. In this paper, Al 7075/bubble alumina syntactic foams were fabricated by recyclable pressure infiltration casting method. Macroscopic and microscopic investigations showed that almost flawless infiltration was obtained between $2-4 \mathrm{~mm}$ hollow bubble alumina spheres and total porosity values of fabricated foams varied between $\% 43.2$ and $\%$ 45.6. As for mechanical analyses, all foam samples were subjected to quasi-static compression test $(1 \mathrm{~mm} / \mathrm{min}$ deformation rate $)$ and their crucial properties such as compression strength, plateau strength, densification strain and energy absorption capacity were determined. Besides, aging heat treatment (T6) was applied to certain samples in order to explore probable effects of heat treatment on the mechanical responses. The outcomes indicated that there was a positive relationship between the aging treatment and compressive features. Under the compressive loading, even though T6 treated foams showed a tendency to brittle fracture, their as-cast variants exhibited ductile behavior.
\end{abstract}

\section{INTRODUCTION}

In recent times, due to their low density, good strength to weight ratio, high stiffness and perfect energy absorption ability, metal matrix syntactic foams (MMSFs) have become considerably attractive for several industrial areas [1,2]. Especially automotive, aviation, aerospace, building/construction and marine sectors give weight to lightweight composite foams instead of traditional metal alloys to lighten constructions, to enhance thermal isolation capacity, to increase total loading capacity and to obtain fuel efficiency. Typically, MMSFs consist of a metallic matrix and hollow or porous ceramic fillers, so these advanced materials can combine the features of particle reinforced composites and close cell metal foams [3]. Because of their relatively low melting temperature and low density, Al alloys are the most preferred matrix materials in the technical literature while $\mathrm{Mg}, \mathrm{Fe}$ and $\mathrm{Zn}$ alloys are also used by some researchers $[1,4,5]$. Contrary to metallic matrix, filler materials are chosen from oxide ceramics in order to enhance mechanical responses particularly compression and impact properties. Engineered hollow ceramics, glasses and fly ash cenospheres are utilized commonly, but recently, some naturel porous ceramics like expanded glass, expanded perlite and pumice have also been investigated by certain research groups [6-9].

MMSFs can be fabricated with a lot of different methods such as stir casting, onward pressure infiltration, backward pressure infiltration, gas/vacuum pressure infiltration and powder metallurgy [6-11]. Since all fabrication techniques have own advantages and handicaps in terms of dimensional accuracy, surface 
quality, production cost, operation duration and ease of application, correct determination of the fabrication method and proper optimization of input variables are notably critical. Thanks to their availability of casting and promising potential, MMSFs have become strong alternatives to traditional particle reinforced metal composites and close cell metal foams for a few years. Lately, studies focusing on AMSFs have gone up in order to comprehend their mechanical responses in depth. For instance, Hao et al. [12] investigated mechanical features of ZL111/alumina syntactic foam filled thin walled tubes and found that the tubes displayed perfect specific energy absorption under axial and radial compression. Goel et al [13] examined high strain rate compression behavior of cenosphere filled Al foam and emphasized that compression strength increased with strain rate. In another effort performed by Sahu et al. [14], cenosphere embedded Al 2014 syntactic foam was fabricated with stir casting. The research team claimed that high yield strength obtained under quasi-static compression could provide some advantages for next investigations. Orbulov et al. [15] used A199.5 and AlSi12 matrix with ceramic hollow fillers to determine compressive properties and low frequency damping capacity of the AMSFs. Akinwekomi et al. [16] manufactured Al/fly ash cenosphere syntactic foams by using powder metallurgy and showed that compressive strength and energy absorption capacity dropped with escalating filler size.

In the present effort, contrary to widely used low alloyed or cast $\mathrm{Al}$ alloys, industrial focused $\mathrm{Al} 7075$ alloy was filtered between high-tech bubble alumina spheres by means of recyclable pressure infiltration technique. In the fabrication stage, our main aim was to recycle excess $\mathrm{Al}$ alloy so as to increase production efficiency in comparison with other methods performed in technical literature. For this purpose, after the separation of the syntactic part, remained metallic section was again added into the melting system. The microstructural and mechanical properties of the fabricated syntactic foams were analyzed in depth. Due to its ability for heat treatment, $\mathrm{Al} 7075$ matrix was subjected to T6 aging treatment to comprehend possible effects of the heat treatment on the mechanical properties and fracture behaviors of the foam samples. Furthermore, as-cast and heat treated samples were analyzed and compared with regards to deformation mechanisms and failure modes.

\section{MATERIAL AND METHOD}

\subsection{Materials}

$\mathrm{Al} 7075$ alloy is usually opted for by automotive, aviation, aerospace, building/construction, defense and outdoor sports industries because of its ductility, high strength, good toughness and corrosion resistance. Aside from its remarkable physical and mechanical properties, Al 7075 is very suitable for aging heat treatment due to its chemical composition in which zinc plays a critical role for emerging of secondary phases $[17,18]$. Therefore, in this investigation, we used Al 7075 as matrix material and Table 1 given below shows chemical composition of supplied Al 7075 according to the supplier information.

Table 1. Chemical composition of Al 7075 matrix

\begin{tabular}{|l|l|l|l|l|l|l|l|}
\multicolumn{6}{|l|}{ Elements (wt. \%) } \\
\hline $\mathrm{Zn}$ & $\mathrm{Mg}$ & $\mathrm{Cu}$ & $\mathrm{Fe}$ & $\mathrm{Si}$ & $\mathrm{Mn}$ & $\mathrm{Ti}$ & $\mathrm{Zr}$ \\
5,68 & 2,39 & 1,4 & 0,21 & 0,2 & 0,18 & 0,034 & 0,018 \\
\hline
\end{tabular}

As to filler material, bubble alumina hollow spheres (Alodur ${ }^{\circledR} \mathrm{KKW}$ ), which were supplied from Imerys Group S.A., were used and their size range was kept constant $(2-4 \mathrm{~mm})$. Basically, bubble alumina is manufactured by fusing high purity alumina. The molten alumina is atomized to create hollow spheres. In addition, it is often used in manufacturing of insulation materials and refractory building elements and as filtration materials for different kinds of liquids. Some physical properties and chemical composition of alumina spheres can be seen in Tables 2 and 3 in detail according to the supplier information. Also, from Table 2, it can be also expressed that owing to its spherical and hollow shape, bubble alumina has a low bulk density and low thermal conductivity compared with the metallic matrix. 
Table 2. Major physical properties of engineered bubble alumina spheres

\begin{tabular}{|l|l|}
\hline Property & Result \\
\hline Melting point $(\mathrm{K})$ & 2323 \\
Thermal conductivity $(\mathrm{W} / \mathrm{m} . \mathrm{K})\left(25^{\circ} \mathrm{C}\right)$ & 0.5 \\
Bulk density $\left(\mathrm{g} / \mathrm{cm}^{3}\right)$ & $0.5-0.75$ \\
Linear expansion coefficient $(1 / \mathrm{K})$ & $8 \times 10^{-6}$ \\
Color & White \\
\hline
\end{tabular}

Table 3. Chemical composition of engineered bubble alumina spheres

\begin{tabular}{|l|l|l|l|l|l|}
\hline \multicolumn{5}{|c|}{ Chemical analysis (wt. \%) } \\
\hline $\mathrm{Al}_{2} \mathrm{O}_{3}$ & $\mathrm{SiO}_{2}$ & $\mathrm{MgO}$ & $\mathrm{Na}_{2} \mathrm{O}$ & $\mathrm{Fe}_{2} \mathrm{O}_{3}$ & $\mathrm{CaO}$ \\
98.8 & 0.8 & 0.01 & 0.1 & 0.03 & 0.03 \\
\hline
\end{tabular}

Prior to main infiltration stage, all alumina fillers were filtered with suitable sieve apparatus and were soaked in distillate water. Floating spheres were singled out because some undesirable broken or damaged spheres were present among them. Separation of defective spheres was highly significant in order to produce high quality foams. In Figure 1, bubble alumina spheres are demonstrated in terms of both macroscopic and microscopic views.
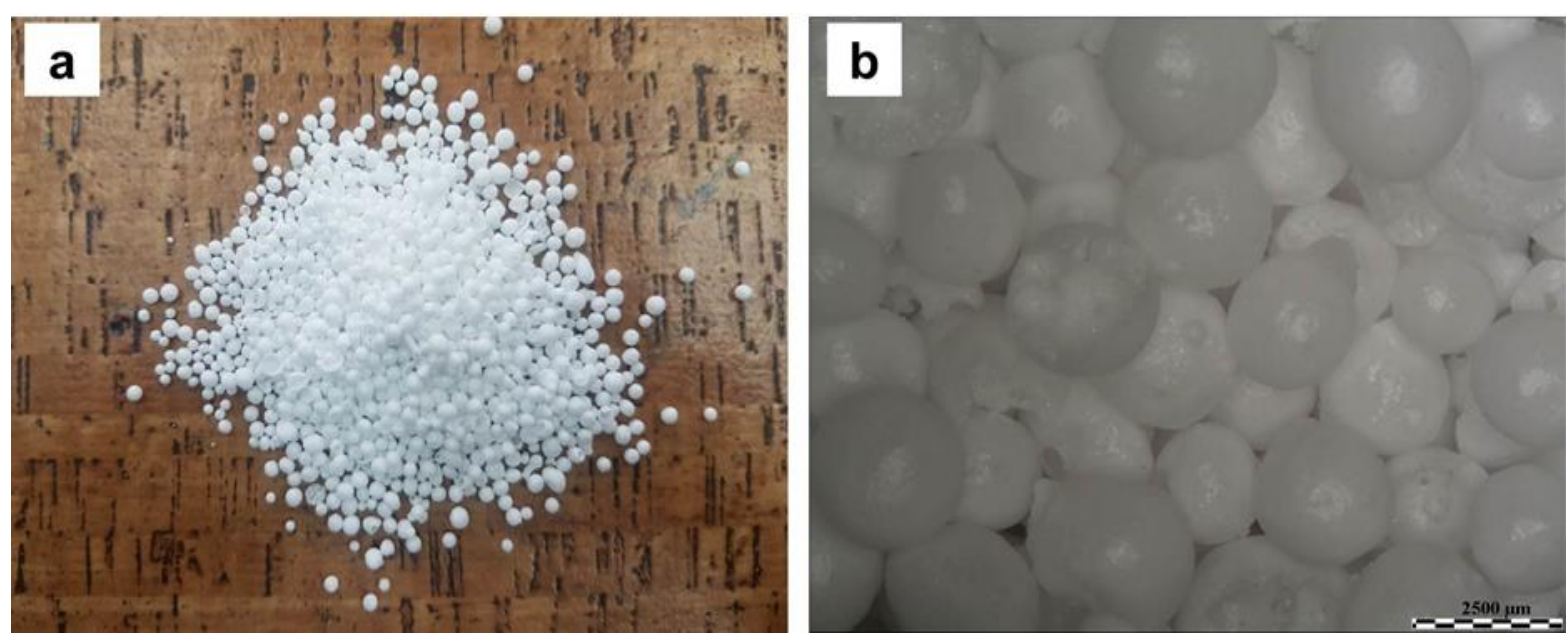

Figure 1. Macro (a) and micro (b) images of bubble alumina spheres

\subsection{Manufacturing Procedure}

Casting technique applied in this research works in the principle of gravity assisted onward pressure infiltration. Schematic diagram of the casting can be seen in Figure 2 in detail. If the method is explained briefly, a resistance furnace $\left(1200^{\circ} \mathrm{C}\right.$ max. capacity) was used for melting of the $\mathrm{Al}$ matrix, preheating of bubble alumina spheres and preheating of sealed steel mold. Firstly, the mold and Al 7075 block were put into the furnace and the furnace was heated up to $720^{\circ} \mathrm{C}$. All components were kept at $720^{\circ} \mathrm{C}$ for $25 \mathrm{~min}$ to ensure complete melting of the matrix and sufficient heating of the mold. The volume of the liquid matrix was more than the volume of the bubble alumina spheres with the intention of full and flawless infiltration during casting. Then, the sealed steel mold was taken out from the furnace, preheated alumina spheres were placed in the mold cavity and the liquid Al alloy was added on for onward pressure infiltration. Following these steps, mechanical pressure of $0.1 \mathrm{MPa}$ was implemented with the help of the steel plunger. The plunger was designed as medium fit because evacuation of excess liquid matrix and ventilation of the system was also significant. After solidification and cooling, the sealed steel mold was opened up and the semi-produced foam sample was removed manually. Finally, in order to achieve desired product dimensions, the semi-produced sample was cut by high speed diamond cutter and the syntactic foam section was separated from full metallic section that was recycled and utilized as matrix source in the next castings. 


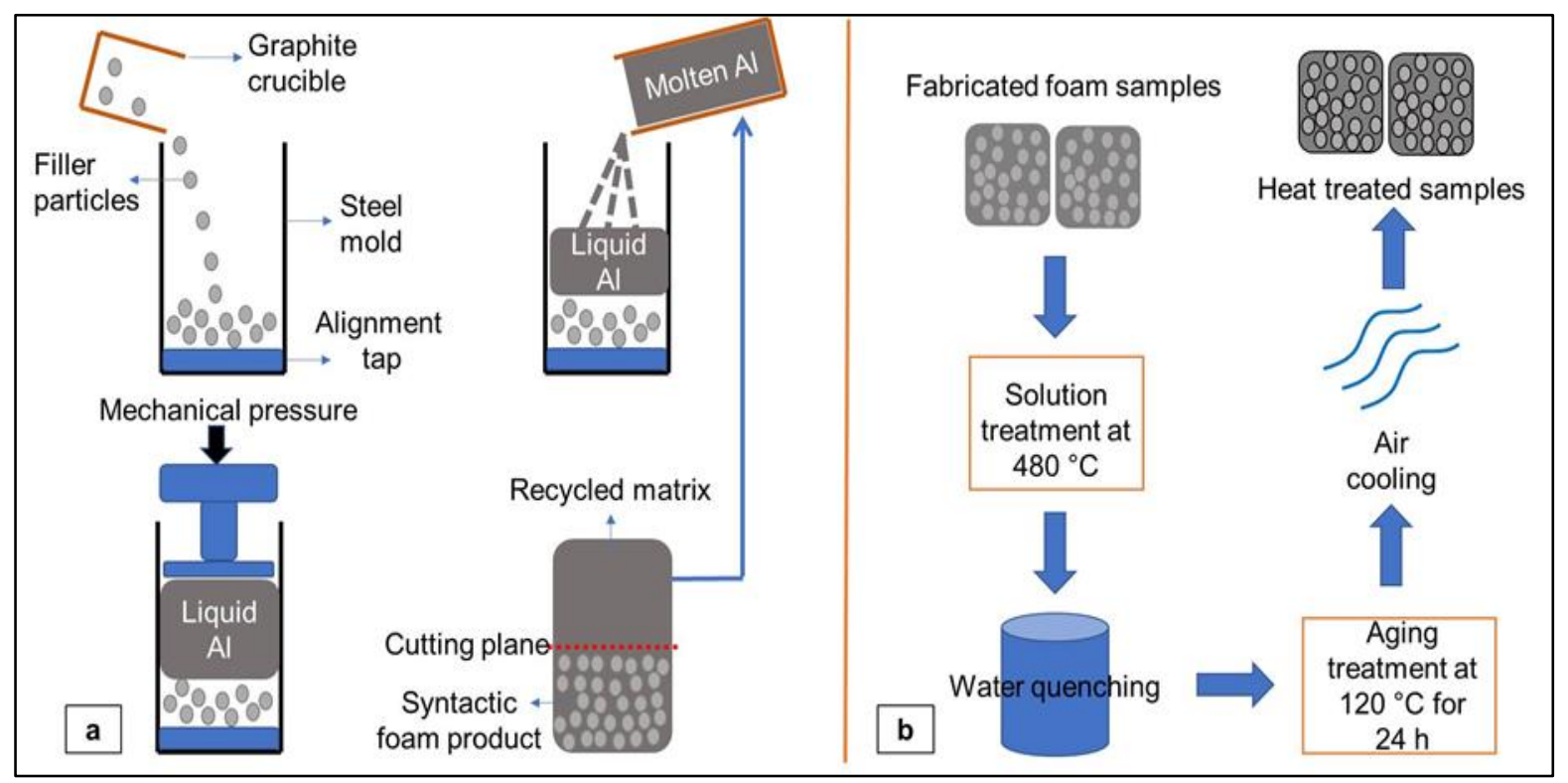

Figure 2. Schematic view of fabrication process (a) and T6 heat treatment steps (b)

All in all, by means of the recyclable pressure infiltration casting, six different cylindrical foams with $25 \pm 0.4 \mathrm{~mm}$ diameter and $30 \pm 0.8 \mathrm{~mm}$ length were manufactured without any problems. For density measurement, sample mass values were divided by their cylindrical volumes. Calculated density values of the all foam samples varied between 1.72 and $1.78 \mathrm{~g} / \mathrm{cm}^{3}$. Samples having near densities were sorted out for T6 heat treatment depicted in Figure 2 that composes of solution treatment at $480^{\circ} \mathrm{C}$ and aging at $120^{\circ} \mathrm{C}$ for $24 \mathrm{~h}$.

\subsection{Characterization Procedure}

In the characterization study, macroscopic and microscopic observations were carried out. At the beginning of the microscopic works, syntactic samples were cut into two pieces and cross sectional faces were grinded with by using silicon carbide emery papers before polishing with diamond suspension. After the polishing, ultrasonic cleaning was carried out as foam surfaces might have some micronized contaminations. With the aim of image analysis, Nikon Eclipse LV150L industrial and Nikon SMZ800 stereo model microscopes were used along with DpxView-Pro software.

With the intention of mechanical investigations, quasi-static compression tests were performed with $50 \mathrm{kN}$ Shimadzu AG-IS uniaxial testing machine. For data acquisition, Trapezium 2 data software was used. Throughout the compression tests, the load and displacement outputs were saved and converted to the engineering stress-strain values thanks to initial sample height and cross sectional area. Based on stressstrain graphs of the foams, plateau stress $\left(\sigma_{\mathrm{ple}}\right)$, compressive strength $\left(\sigma_{\mathrm{cmp}}\right)$, densification strain $\left(\mathcal{E}_{\mathrm{dsf}}\right)$ and total energy absorption (W) values were appointed. Besides, all mechanical tests were recorded with a digital camera so as to comprehend deformation characteristics of samples.

For volumetric characterization, volume fraction of filler particles $\left(\mathrm{F}_{\text {fil }}\right)$ and total porosity percentage $\left(\mathrm{F}_{\mathrm{TP}}\right)$ were calculated using some mathematical expressions written below [6]. In the Equation (1), Equation (2) and Equation (3); $\mathrm{V}_{\text {syn }}, \mathrm{m}_{\text {syn }}, \mathrm{m}_{\mathrm{fil}}, \rho_{\text {alu }}$ and $\rho_{\text {sd }}$ are the syntactic foam volume, the foam mass, the mass of alumina spheres, density of the matrix and density of solid state of the spheres respectively

$$
\begin{aligned}
\mathrm{F}_{\text {fil }} & =\left[\left(\mathrm{V}_{\mathrm{syn}}-\left(\mathrm{m}_{\text {syn }}-\mathrm{m}_{\mathrm{fil}}\right) / \rho_{\text {alu }}\right) / \mathrm{V}_{\text {syn }}\right] \cdot 100 \\
\rho_{\text {fil }} & =\mathrm{m}_{\mathrm{fil}} /\left[\mathrm{V}_{\text {syn }}-\left(\mathrm{m}_{\mathrm{syn}}-\mathrm{m}_{\mathrm{fil}}\right) / \rho_{\mathrm{alu}}\right] \\
\mathrm{F}_{\mathrm{TP}} & =\mathrm{F}_{\text {fil }} \cdot\left[1-\left(\rho_{\mathrm{fil}} / \rho_{\mathrm{sd}}\right)\right] .
\end{aligned}
$$




\section{THE RESEARCH FINDINGS AND DISCUSSION}

\subsection{Macro and Micro Examinations}

Manufactured foams were inspected elaborately in terms of both macro and micro features. First of all, immediately after the fabrication, visual inspection was performed for detection of surface flaws or contaminations. Then, macro observations were carried out to analyze inner structure and dimensional accuracy. Figure 3 depicts macro views of foam samples from different perspectives.

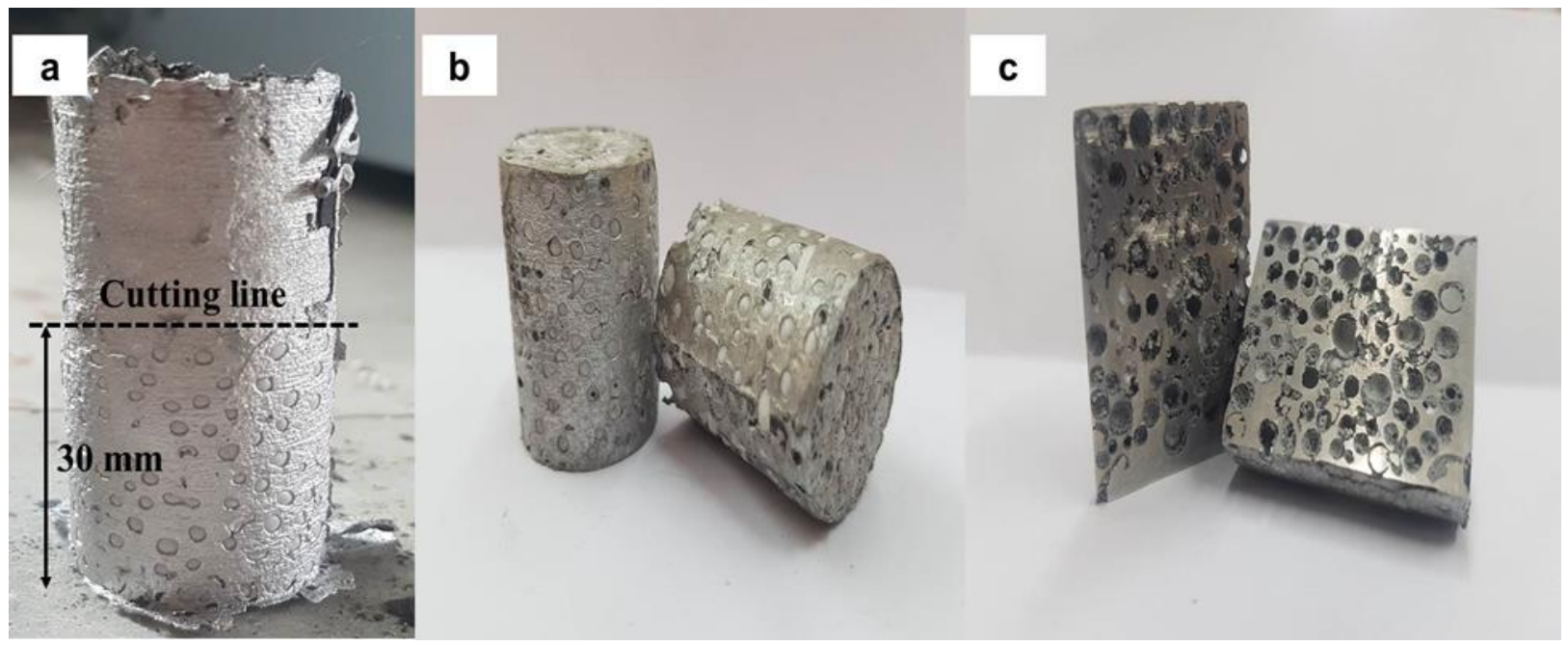

Figure 3. Different views of fabricated syntactic foams: semi product (a), full product (b) and cross sectional view (c)

As a result of these observations, it was clear that by way of the recyclable pressure infiltration there was no cracks and pits on all foam surfaces. Also, uniform filler distribution and sufficient infiltration even in narrow zones were observed following the cross sectional analysis. As the two-pieced sealed steel mold was used, all syntactic samples carried split lines on their lateral surfaces symmetrically and in some cases, excess burrs around the bottom face of the samples were observed. However, all of these minor imperfections were solved with effective grinding and polishing treatments.

Fabricated syntactic foams were divided into two groups and categorized with tags of as-cast (SF1, SF2 and SF3) and T6 heat treated (SF4, SF5 and SF6). Table 4 shows density values of the syntactic samples as well as volume fraction of the fillers and total porosities. Depending upon physical characterization, foam densities fluctuate between 1.72 and $1.78 \mathrm{~g} / \mathrm{cm}^{3}$ with the average of $1.74 \mathrm{~g} / \mathrm{cm}^{3}$. These results are relatively low and quite compatible with other previous literature investigations practiced with alumina fillers $[19,20]$. Compared to other kinds of filler materials used in technical papers, even though bubble alumina has higher density value, it displays superior mechanical properties under the compressive loadings. Engineered bubble alumina spheres used in this study have thin walled hollow structure, so calculation of the foam porosity considerably relates to porosity levels of alumina spheres. The results indicate that SF2 and SF3 possess the highest porosity levels with \% 45.6 although SF1 has the lowest with $\%$ 43.2. Total foam porosity values are also parallel with filler volume fractions in the manufactured foams. According to the volumetric calculations, filler volume fractions range between $\% 62.8$ and $\% 60.1$ (with average of $\% 61.8)$.

The typical microstructure of the investigated $\mathrm{Al}$ 7075/bubble alumina syntactic foams are given in Figure 4 and it is largely compatible with general AMSF structures defined in former scientific investigations [1, 2]. It is obvious from Figure 4, fabricated foams comprise of two main phases (metallic matrix and hollow alumina spheres) and some minor phases (casting voids, broken sphere fragments and matrix filled spheres). By reason of difference in thermal conductivity between the Al matrix and alumina fillers, total solidification time shows decreasing tendency from matrix/filler interface to the matrix. This circumstance can lead to certain small shrinkage cavities near the matrix/filler interface. Apart from that, sometimes, 
some broken fillers may get in faultless particles before the fabrication (Figure 4b), which can cause unwanted density increment. Also, in some instances (for example SF1), the molten Al matrix may penetrate into the filler gaps owing to local defective points on the filler surface. A fair amount of molten Al penetration into the spheres is not only responsible for the density rising but it can also alter the compressive properties and failure modes.

Table 4. Physical properties of foam samples

\begin{tabular}{|l|l|l|l|}
\hline Foam No & Foam density $\left(\mathbf{g} / \mathbf{c m}^{\mathbf{3}}\right)$ & Filler volume fraction $(\boldsymbol{\%})$ & Total porosity $(\boldsymbol{\%})$ \\
\hline SF1 & 1.78 & 60.1 & 43.2 \\
SF2 & 1.72 & 62.8 & 45.6 \\
SF3 & 1.74 & 62.7 & 45.6 \\
SF4 (T6) & 1.77 & 61 & 43.3 \\
SF5 (T6) & 1.74 & 62.1 & 44.7 \\
SF6 (T6) & 1.73 & 62.4 & 45.1 \\
\hline
\end{tabular}

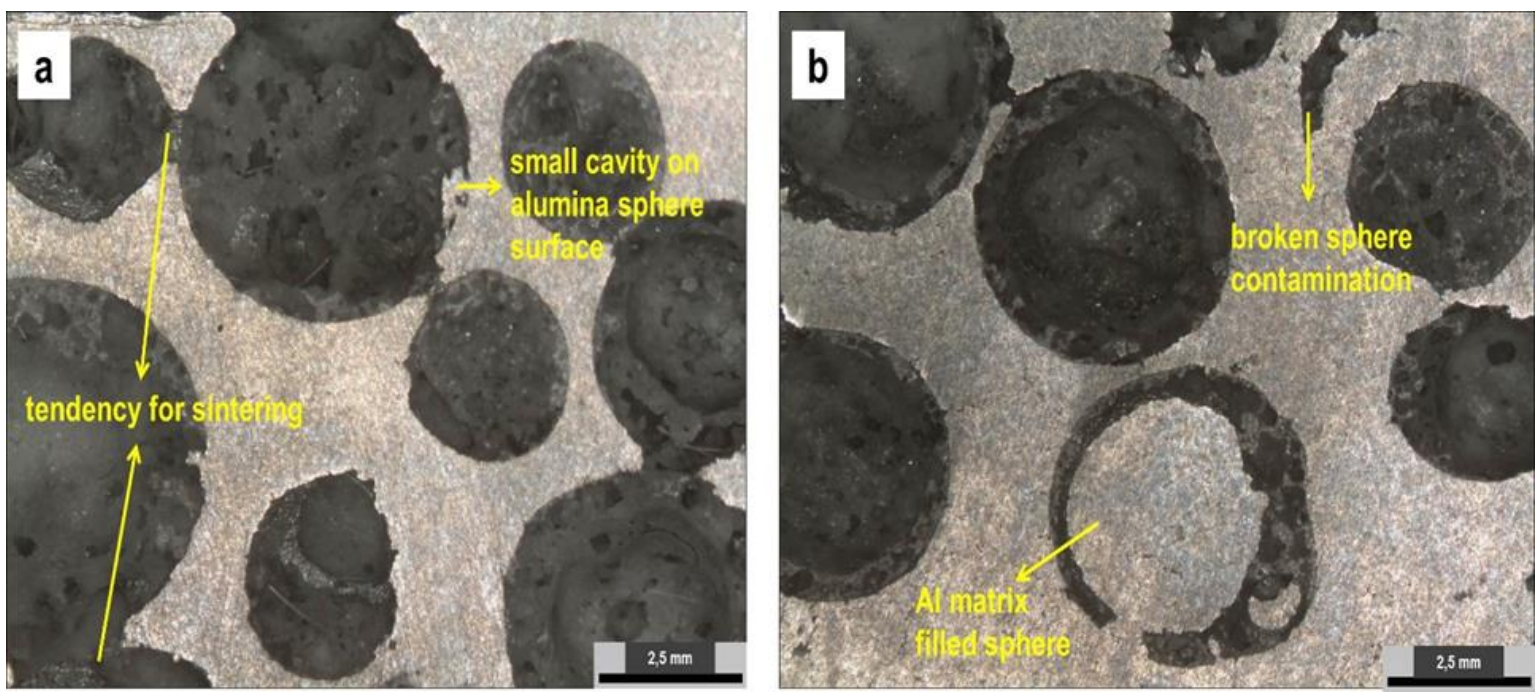

Figure 4. Micro views of fabricated syntactic foams

Throughout the fabrication, it can be expressed that depending upon volumetric distribution of the alumina spheres, which is majorly homogenous in the foam body structure, certain spheres show combining tendency to each other and become larger size hollow spheres. This circumstance can also be explicated as a partial sintering and is noticed almost in all fabricated foam samples (Figure 4a). On the other hand, fillers with high content of $\mathrm{SiO}_{2}$ have a potential of chemical reaction around the matrix/filler interfaces [21]. However, since alumina spheres with low $\mathrm{SiO}_{2}$ were used and the casting process was performed at low temperature with rapid solidification time (approximately $40 \mathrm{sec}$.) any chemical activity between the matrix and filler materials was not detected. In brief, if the macroscopic and microscopic observations are considered together, it is evident that perfect matrix/filler harmony can be created by means of recyclable pressure infiltration casting.

\subsection{Mechanical Properties}

Principally, the standard of ISO 13314 is taken into consideration for interpretation of compressive properties of AMSFs. [22]. According to the standard, compressive (\%1 proof) strength $\left(\sigma_{\mathrm{cmp}}\right)$ is described as a value at a plastic compressive strain of $\% 1$ and plateau stress $\left(\sigma_{\mathrm{ple}}\right)$ is arithmetical mean of the stresses between \% 20 and \% 40 strain. In addition, energy absorption (W) and energy absorption efficiency ( $\eta$ ) values can be calculated with following Equations (4) and (5). Table 5 written below shows all of the major compressive properties together. 


$$
\begin{gathered}
W=\int_{0}^{0.5} \sigma \cdot d \varepsilon \\
\eta=\frac{W}{\sigma_{\text {max }} \times 0.5}
\end{gathered}
$$

Table 5. Mechanical properties of foam samples

\begin{tabular}{|l|l|l|l|l|l|}
\hline Foam No & $\boldsymbol{\sigma}_{\text {cmp }}(\mathbf{M P a})$ & $\boldsymbol{\sigma}_{\text {ple }}(\mathbf{M P a})$ & $\boldsymbol{\varepsilon}_{\text {dsf }}$ & $\mathbf{W}\left(\mathbf{M J} / \mathbf{m}^{\mathbf{3}}\right)$ & $\mathbf{\eta}(\mathbf{\%})$ \\
\hline SF1 & 28.3 & 36.2 & 0.56 & 16.9 & 0.89 \\
\hline SF2 & 19.1 & 26.6 & 0.51 & 12.2 & 0.84 \\
\hline SF3 & 22.3 & 39.2 & 0.52 & 17.5 & 0.73 \\
\hline SF4 & 71.2 & 60.9 & 0.53 & 27.8 & 0.76 \\
\hline SF5 & 44.4 & 42.9 & 0.51 & 20.5 & 0.91 \\
\hline SF6 & 39.8 & 49.3 & 0.49 & 24.9 & 0.87 \\
\hline
\end{tabular}

The compression tests were performed on six different samples and three of them were subjected to aging treatment. Engineering stress-strain curves of the syntactic foams can be followed from Figure 5. Looking at these curves carefully, foam samples display predicted mechanical response including of three characteristic regions just as experienced for other AMSFs. In the initial region, elastic deformation takes place linearly and stress rising is quite apparent. Secondly, immediately after the linear region, plateau behavior starts. In this stage, stress values may keep constant or may fluctuate according to matrix/reinforcement combination. At last region that is called densification area, stress values escalate swiftly in virtue of diminishment of total porosity level in the foam structure.

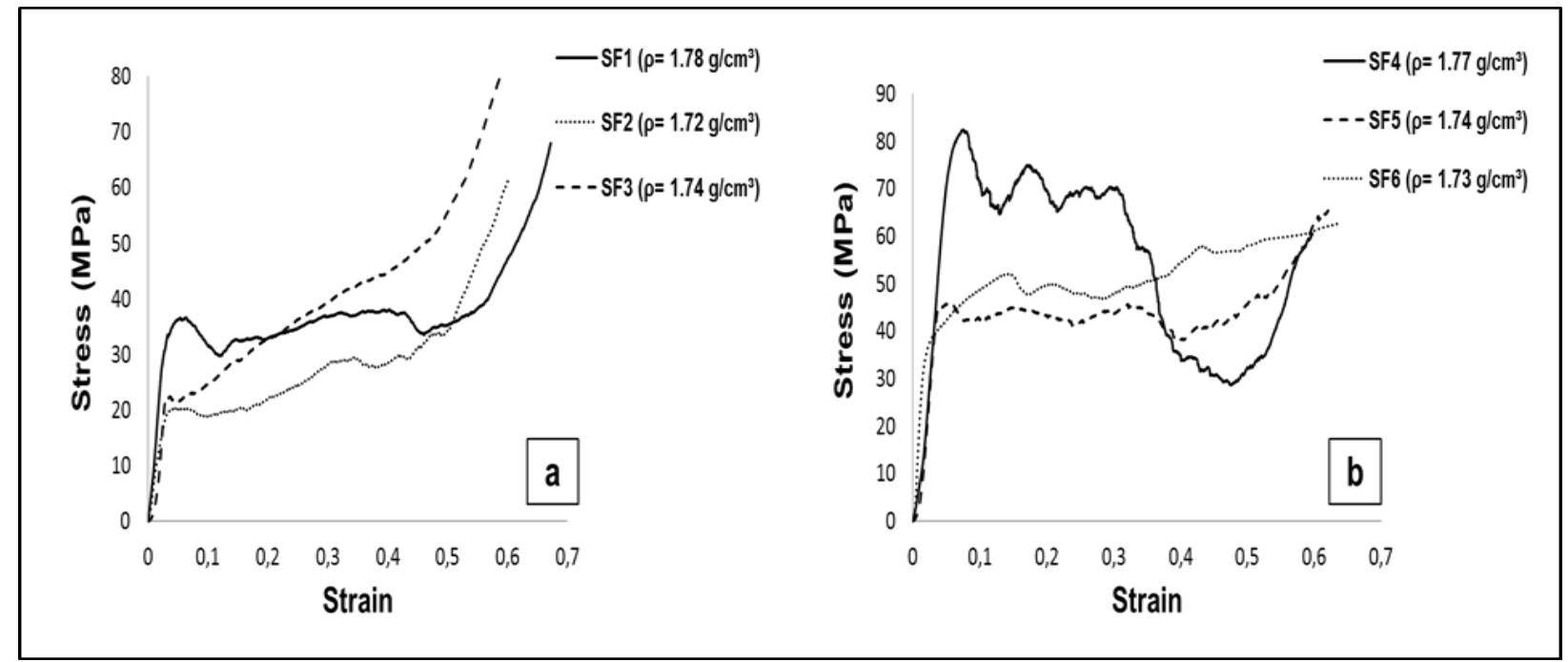

Figure 5. Engineering stress-strain curves of the fabricated samples: As-cast (a) and aging treated (b)

The compression strength values of aging treated foams surpass the relevant values for as-cast foams irrespective of the reinforcement type because, following the T6 treatment, precipitation of secondary phases in the Al matrix blocks dislocation movements and leads to hardness increment. During the compressive deformation, the $\mathrm{Al}$ alloy matrix bears most of the load while bubble alumina spheres are not effective enough. Certain major compressive responses calculated in this research are shown in Figure 6. 
In this context, peak value of the compression strength is $71.2 \mathrm{MPa}$ for aging treated SF4 and it is followed by SF5 and SF6. Moreover, there is an affirmative relation between the foam density and the compression strength (Figure 6a). This case can be explained by decreasing porosity levels of foam samples and increasing volume fraction of $\mathrm{Al}$ matrix.

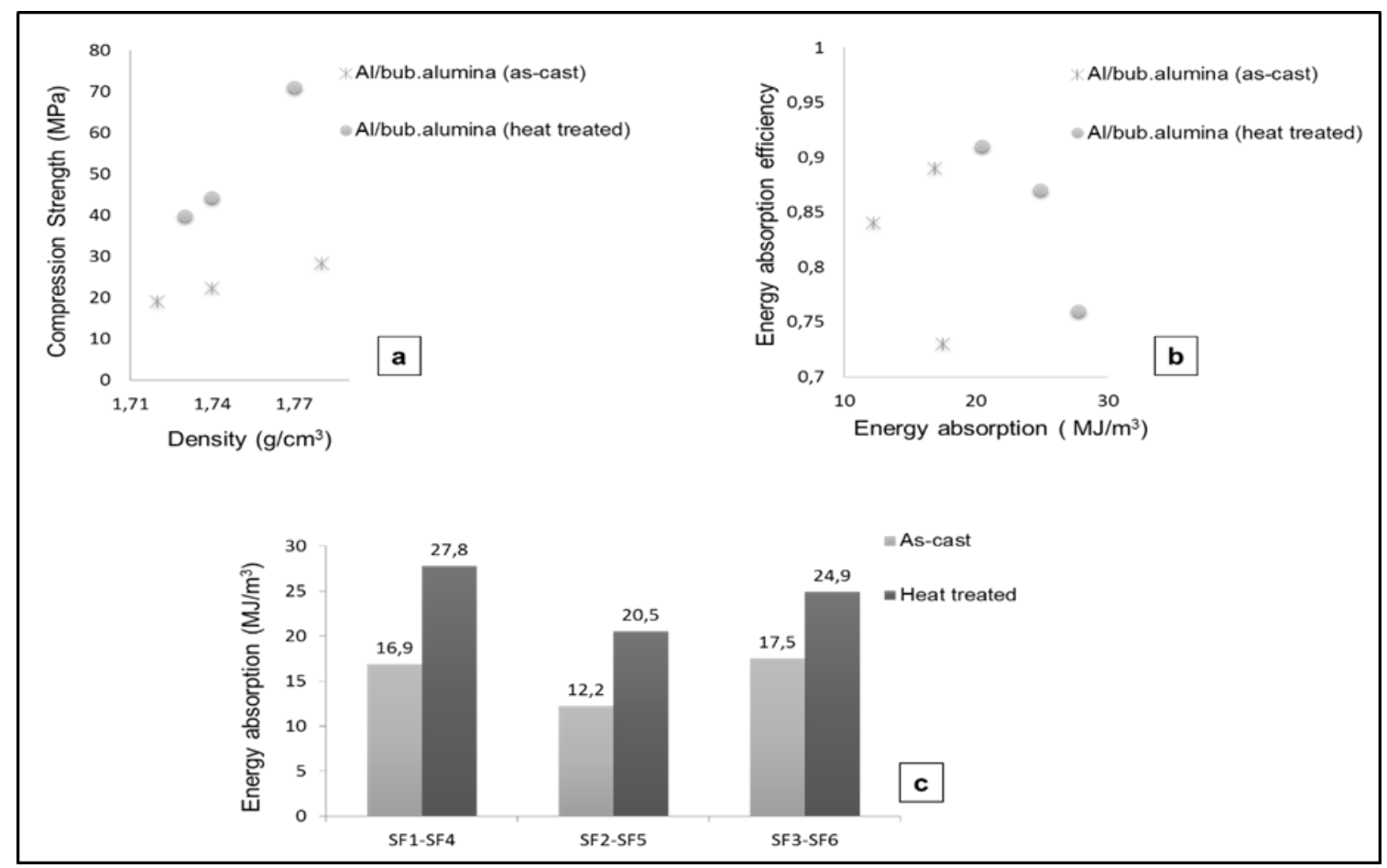

Figure 6. Compressive properties of bubble alumina reinforced syntactic foams: compression strength (a), energy absorption and efficiency $(b)$, energy absorption (c)

In the stress/strain graph, the plateau region is an area where the main plastic deformation and crushing of the syntactic foam occur at constant or fluctuating stresses. Therefore, the plateau stress $\left(\sigma_{\mathrm{ple}}\right)$ is a crucial property of AMSFs that plays an important role for ability of energy absorption during large-strain compression. Similar to compression strength, the aging treatment also affects the plateau behavior positively and plateau stresses of the aging treated foams are obviously higher than these of the as-cast foams. Table 5 reports the plateau stress results for all fabricated samples. The highest and lowest plateau stresses are observed for aging treated sample of SF4 and as-cast sample of SF2 (60.9 MPa and 26.6 MPa). In theory, constant stress level in the plateau zone is an ideal response for traditional metal foams, but for syntactics, this situation usually changes due to the filler properties like pore structure, pore distribution, shell strength and chemical composition. From Figure 5, SF5 has the flattest stress-strain graph in its plateau zone hence it is not difficult to anticipate that maximum energy efficiency can be obtained for SF5.

The energy absorption capacity is highly critical for many engineering applications and some investigations on the traditional composite materials and foams have already been conducted [23-25]. This feature is also one of the most significant properties of AMSFs and strongly depends on plateau behavior. According to energy calculations illustrated in Figure 6, the aging treated syntactic foams clearly present superior results from the point of energy absorption ability in comparison with their as-cast versions having similar densities. The difference between the two groups may be explained with relatively high compressive and plateau strength values of aging treated foams despite a noteworthy fall in the matrix ductility. From Figure 6, the most dramatic energy absorption rising can be noticed between SF2 and SF5 $\left(8.3 \mathrm{MJ} / \mathrm{m}^{3}\right.$, approximately \% 68) in spite of the fact that the lowest increase is calculated between SF3 and SF6 (7.4 $\mathrm{MJ} / \mathrm{m}^{3}$, approximately \% 42).

At the densification point (plateau end point), maximum strain of 0.56 belongs to SF1 although minimum value of 0.49 determined for SF6. Regardless of the aging treatment, all samples show adequate elongation and almost reach \% 50 strain under the compressive loadings. Herein, it can be brought forward that bubble 
alumina spheres don't show anisotropic deformation behavior in the plateau region owing to their good roundness and almost identical inner structures.

In general, there is a common standpoint that the principle mechanical properties $\left(\sigma_{\mathrm{cmp}}, \sigma_{\mathrm{ple}}, \varepsilon_{\mathrm{dsf}}\right.$ and $\left.\mathrm{W}\right)$ of AMSFs enhance with the density. Usually, as long as AMSF density values go up the mechanical properties also increase. As a probable explanation for this approach, high volume fraction of metallic matrix, homogeneous filler distribution and high particle roundness can be put forward. Nevertheless, sometimes, some small differences in the mechanical features may be detected among close/same density foams due to heterogeneous distribution of fillers and undesirable contamination of defective particles.

In consequence of efficiency calculations, it can be expressed that the energy absorption efficiency is an output being independent from the syntactic foam density just like other investigators pointed in the past [5]. Calculated efficiency values vary between 0.73 (SF3) and 0.91 (SF5) and they enormously depend on the plateau behavior of the samples. In addition, if the as-cast samples with the average of 0.82 are compared with heat treated samples with the average of 0.85 , it can be asserted that aging treatment doesn't affect energy efficiency in a noteworthy manner.

\subsection{Failure Mechanism}

As for failure mechanism, under the compressive loading, there are two principle failure modes for AMSFs depicted in Figure 7.

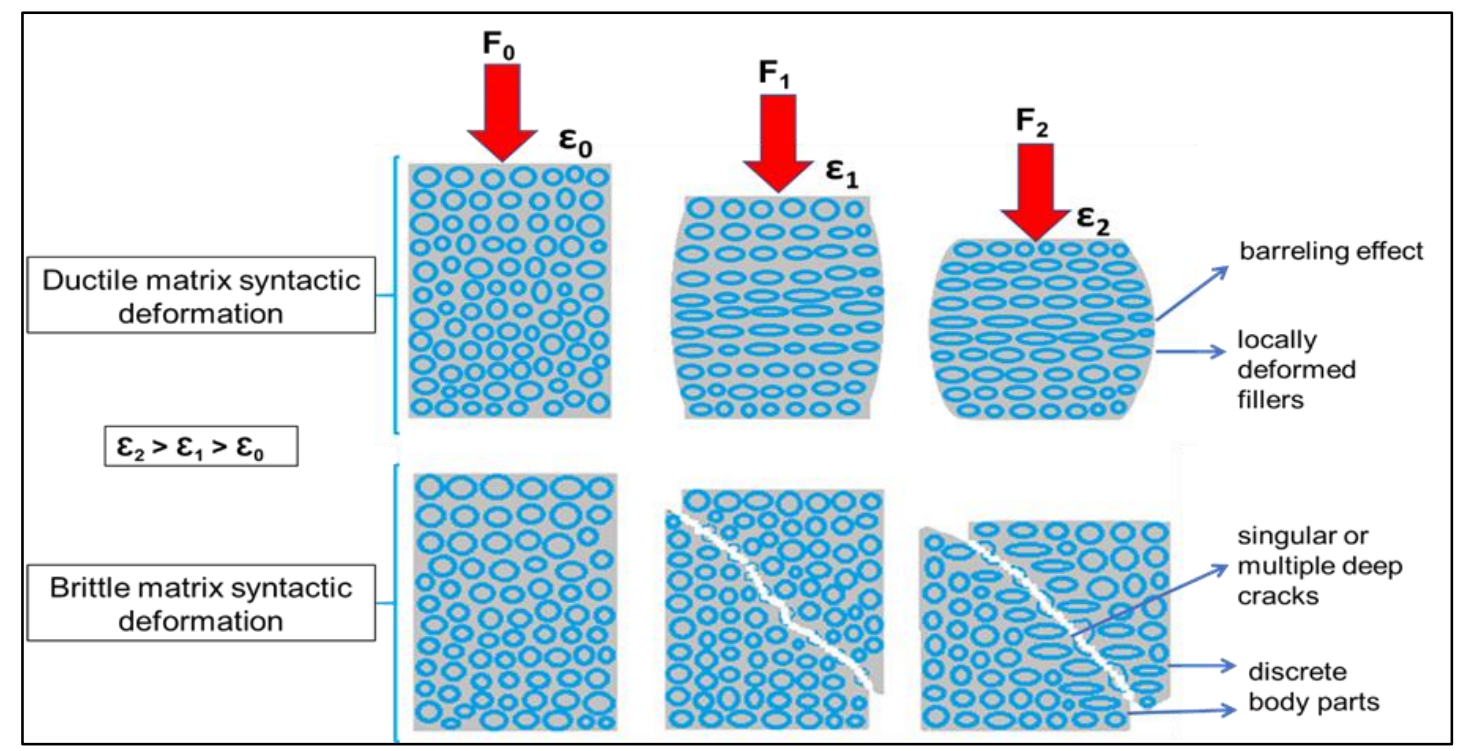

Figure 7. Main deformation mechanisms for AMSFs

Depending upon matrix-filler matching, ductile or brittle manner deformation occurs and the main failure mode is controlled by yield strength of $\mathrm{Al}$ matrix and crush strength of filler particles [15]. If the matrix yield strength doesn't exceed the filler crush strength, the failure mode of the syntactic foam has ductile characteristic owing to face centered cubic structure of the matrix [26], but if the exact opposite of that happens because of some other reasons like heat treatment or surface modifications, the foam tends to brittle fracture.

Figure 8 demonstrates failure images which were taken during the compressive deformation of foam samples. When the Figure 8 is analyzed carefully, it can be seen that at first, deformation force rises sharply and all bubble alumina reinforced foam samples deform in elastic manner regardless of the aging treatment. In parallel with some literature studies [27, 28], right after the first maximal point (peak stress), stress values drop prominently for all fabricated samples owing to simultaneous failure and identical structural properties of alumina spheres. 


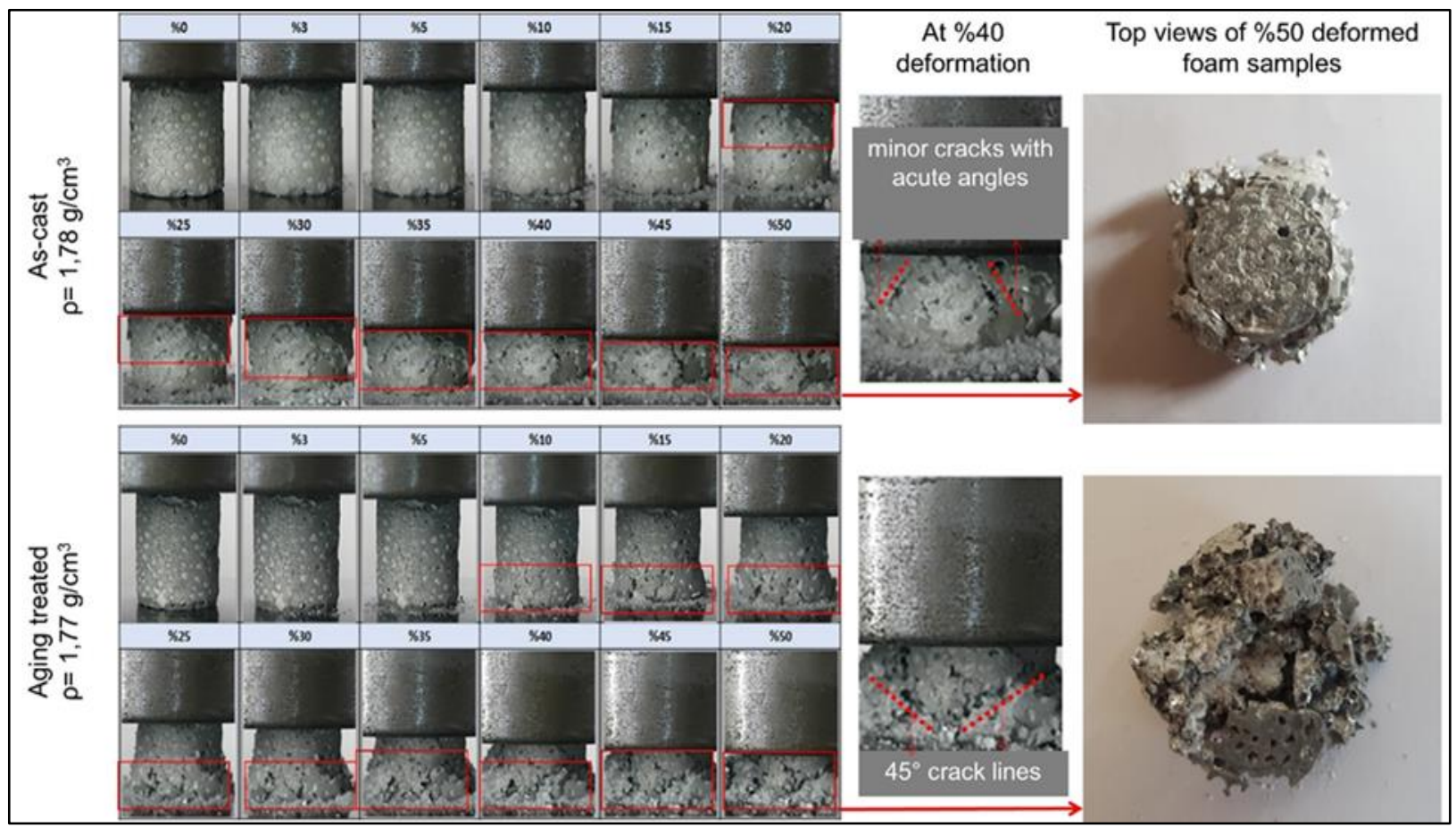

Figure 8. Deformation mechanism of bubble alumina reinforced syntactic foams

Preliminary surface cracks and apparent shear bands at angle of approximately $30-45^{\circ}$ emerge for the ascast and the aging treated samples in \% 20 and \% 10 strain values respectively. Looking at the matrix deformation style and first surface cracks, difference between the as-cast and the aging treated foams can be followed easily. For the as-cast foam, following \% 20 deformation, barreling effect is seen owing to ductile matrix structure, hence except from a few small surface cracks, there are no deep/large cracks on the sample body till \% 40 strain. As long as the deformation continues and the sample height decreases gradually, main collapse is noticed distinctively at the upper part of the sample whereas its bottom half remains comparatively less deformed. However, if the failure behavior of the aging treated sample is scrutinized, between $\% 10$ and \% 50 deformation, the main failure emerges at bottom part of the sample while its upper part bulges slightly. Herein, it is likely that the bottom sections of the foam have higher porosity, which weakens load bearing layers in the aging treated foam and a similar case is also valid for the upper side of the as-cast foam. Moreover, as the aging treatment improves yield strength of the $\mathrm{Al}$ alloy and restricts dislocation movements in the matrix grains, multiple individual cracks propagating rapidly are observed on the foam body throughout the plastic deformation.

After the densification, when the compression test is finished, it is true to say that aging treatment affects largely the failure mode of the Al/bubble alumina syntactic foam. By reason of the aging, Al matrix gains more brittle character, so the heat treated foam breaks into a few discrete parts compared to the as-cast foam remaining nearly single piece (Figure 8). This result can be interpreted that the heat treatment enhances mechanical properties like compression strength, plateau strength and energy absorption, but at the same time, it worsens ductility and fracture toughness of the syntactic foam. In contrast to the heat treated foam, $\mathrm{Al}$ matrix in the as-cast foam behaves in a ductile manner and that state is a possible explanation of mono block structure of the sample after the deformation.

\section{RESULTS}

In this paper, bubble alumina reinforced $\mathrm{Al} 7075$ syntactic foams were manufactured via recyclable pressure infiltration casting on the purpose of understanding of their mechanical, physical and microstructural properties. As a result of our efforts, the followings can be reached;

- Recyclable pressure infiltration casting is a promising technique for production of AMSFs having bubble alumina fillers. Micro observation works point that almost perfect infiltration can be attained at $720^{\circ} \mathrm{C}$ with the applied pressure of $0.1 \mathrm{MPa}$. 
- Density values of the fabricated samples vary between $1.72 \mathrm{~g} / \mathrm{cm} 3$ and $1.78 \mathrm{~g} / \mathrm{cm}^{3}$.

- As long as the foam density goes up, compression strength gains upward tendency. Due to the fact that heat treatment increases matrix strength, T6 treated foams have higher compression strength.

- Plateau stress is a prominent parameter for AMSFs because of its serious influence on the energy absorption. The highest plateau stress belongs to the aging treated sample of SF4 with $60.9 \mathrm{MPa}$.

- Energy absorption ability is directly affected by the aging in a positive manner and all T6 treated samples exhibit better performance in comparison with as-cast foams.

- There is no major difference between the aged and as-cast foams on the energy absorption efficiency. Among the all six fabricated foams, the peak value of $\% 91$ is reached by SF5.

- The aging treatment converts the failure mode of the fabricated foams from ductile deformation to brittle fracture.

- When the compressive deformation is finished, even though the as-cast version of the foam remains monolithic, the $\mathrm{T} 6$ treated foam breaks into small or middle size individual pieces owing to high brittleness of the $\mathrm{Al}$ matrix.

\section{ACKNOWLEDGEMENTS}

We thank intimately Imerys Group S.A for supplying high-tech bubble alumina spheres rapidly and their assistance throughout our fabrication studies.

\section{CONFLICTS OF INTEREST}

No conflict of interest was declared by the authors.

\section{REFERENCES}

[1] Gupta, N., Luong, D.D., Cho, K., "Magnesium matrix composite foams- Density, mechanical properties, and applications", Metals, 2(3): 238-252, (2012).

[2] Orbulov, I. N., Szlancsik, A., "On the mechanical properties of aluminum matrix syntactic foams", Advanced Engineering Materials, 20(5), (2018).

[3] Rohatgi, P. K., Gupta, N., Schultz B. F., Luong, D. D., “The synthesis, compressive properties, and applications of metal matrix syntactic foams", Journal of Materials, 63: 36-42, (2011).

[4] Castro, G., Nutt, S. R., "Synthesis of syntactic steel foam using gravity-fed infiltration", Materials Science and Engineering A, 553: 89-95, (2012).

[5] Movahedi, N., Murch, G. E., Belova, I.V., Fiedler, T., "Effect of heat Treatment on the compressive behavior of zinc alloy ZA27 syntactic foam", Materials, 12(5): 792, (2019).

[6] Taherishargh, M., Belova, I.V., Murch, G. E., Fiedler, T., "Low-density expanded perlite-aluminum syntactic foam", Materials Science and Engineering A, 604: 127-134, (2014).

[7] Tao, X. F., Zhang, L. P., Zhao, Y. Y., "Al matrix syntactic foam fabricated with bimodal ceramic microspheres", Materials and Design, 30(7): 2732-2736, (2009).

[8] Su, M., Wang, H., Hao, H., "Compressive properties of aluminum matrix syntactic foams prepared by stir casting method", Advanced Engineering Materials, 21(8), (2019).

[9] Zhang, Q., Lee, P. D., Singh, R., Wu, G., Lindley, T.C., "Micro-CT characterization of structural features and deformation behavior of fly ash/aluminum syntactic foam", Acta Materialia, 57(10): 3003-3011, (2009). 
[10] Mondal, D. P., Majumder, J.D., Jha, N., Badkul, A., Das, S., Patel, A., Gupta, G., "Titaniumcenosphere syntactic foam made through powder metallurgy route", 34: 82-89, (2012).

[11] Orbulov, I. N., Dobránszky, J., "Producing metal matrix syntactic foams by pressure infiltration", Periodica Polytechnica Mechanical Engineering, 52(1): 35-42, (2008).

[12] Su, M., Wang, H., Hao, H., "Axial and radial compressive properties of alumina-aluminum matrix syntactic foam filled thin-walled tubes”, Composite Structures, 226, (2019).

[13] Goel, M. D., Parameswaran, V., Mondal, D. P., "High strain rate response of cenosphere-filled aluminum alloy syntactic foam", Journal of Materials Engineering and Performance, 28: 4731-4739, (2019).

[14] Sahu, S., Zahid Ansari, M., Mondal, D. P., Cho, C., "Quasi-static compressive behavior of aluminum cenosphere syntactic foams", Materials Science and Technology, 35(7): 856-864, (2019).

[15] Katona, B., Szlancsik, A., Tábi, T., Orbulov, I. N., "Compressive characteristics and low frequency damping of aluminum matrix syntactic foams", Materials Science and Engineering A, 739: 140-148, (2019).

[16] Akinwekomi, A. D., Adebisi, J. A., Adediran, A. A., "Compressive characteristics of aluminum-fly ash syntactic foams processed by microwave sintering", Metallurgical and Materials Transactions A, 50(9): 4257-4260, (2019).

[17] ASM Handbook, Volume 4: Heat Treating, ASM Handbook Committee, 841-879.

[18] Imran, M., Khan, A.R.A., "Characterization of Al-7075 metal matrix composites: a review”, Journal of Materials Research and Technology, 8(3): 3347-3356, (2019).

[19] Licitra, L., Luong, D. D., Strbik III, O. M., Gupta, N., "Dynamic properties of alumina hollow particle filled aluminum alloy A356 matrix syntactic foams", Materials and Design, 66: 504-515, (2015).

[20] Mondal, D. P., Goel, M. D., Upadhyay, V., Das, S., Singh, M., Barnwal, A. K., "Comparative study on microstructural characteristics and compression deformation behavior of alumina and cenosphere reinforced aluminum syntactic foam made through stir casting technique", Transactions of the Indian Institute of Metals, 71: 567-577, (2018).

[21] Balch, D. K., Dunand, D. C., "Load partitioning in aluminum syntactic foams containing ceramic microspheres", Acta Materialia, 54(6): 1501-1511, (2006).

[22] Standardization, IOf, "Mechanical testing of metals-Ductility testing-Compression test for porous and cellular metals", in Geneva, Switzerland, (2011).

[23] Ali, H. F., Akrami, R., Fotouhi, S., Pashmforoush, F., Fragassa, C., Fotouhi, M., "Effect of the stacking sequence on the impact response of carbon-glass/epoxy hybrid composites", Facta Universitatis series: Mechanical Engineering, 18(1): 69-77, (2020).

[24] Lu, X., Zhang, Z., Du, H., Luo, H., Mu, Y., Xu, J., "Compressive behavior of Mg alloy foams at elevated temperature", Journal of Alloys and Compounds, 797: 727-734, (2019). 
[25] Mahdi, E., Ochoa, D., Vaziri, A., Eltai, E., "Energy absorption capability of date palm leaf fiber reinforced epoxy composites rectangular tubes", Composite Structures, 224, (2019).

[26] Dmitriev, S. V., Bayazitov, A. M., Korznikova, E. A., Bachurin, D. V., Zinovev, A. V., "Dynamics of supersonic N-crowdions in fcc metals", Reports in Mechanical Engineering, 1(1): 54-60, (2020).

[27] Balch, D. K., O’Dwyer, J. G., Davis, G. R., Cady, C. M., Gray III, G. T., Dunand, D. C., "Plasticity and damage in aluminum syntactic foams deformed under dynamic and quasi-static conditions", Materials Science and Engineering A, 391(1-2): 408-417, (2005).

[28] Dou, Z.Y., Jiang, L.T., Wu, G. H., Zhang, Q., Xiu, Z.Y., Chen, G. Q., "High strain rate compression of cenosphere-pure aluminum syntactic foams", Scripta Materialia, 57(10): 945-948, (2007). 